\title{
Essential Oils, an Answer to the Dilemma of Multiply Resistant Bacteria?
}

\author{
Beth Bygall ${ }^{1}$, Rebecca A Baker ${ }^{2}$, Ronald Bashore ${ }^{1}$, Linda L Weihbrecht ${ }^{3}$ and Robert L Sautter ${ }^{4 *}$ \\ ${ }^{1}$ Previous Technologist at Pinnacle Health Laboratories, USA \\ ${ }^{2}$ Lancaster, USA \\ ${ }^{3}$ UPMC Pinnacle, Harrisburg, USA, \\ ${ }^{4}$ RLSautter Consulting LLC Lancaster, USA
}

*Corresponding author: Robert L Sautter, RL Sautter Consulting LLC, 3049 Burgess Dr. Lancaster SC 29720, USA

To Cite This Article: Bygall Beth, Rebecca A Baker, Ronald Bashore, Linda L. Weihbrecht, and Robert L Sautter. Essential Oils, an Answer to the Dilemma of Multiply Resistant Bacteria? 2020 - 8(4). AJBSR.MS.ID.001290. DOI: 10.34297/AJBSR.2020.08.001290.

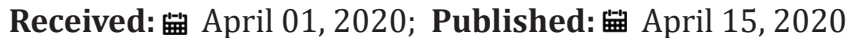

\begin{abstract}
Antibiotic resistance is an increasing worldwide phenomenon. Recently, there has been an interest in using essential oils (EO) both in and out of the hospital. Most current research concentrates on the antimicrobial activity of Tea tree. The purpose of this study is to evaluate the activity of 10 EO, (Tea tree, Thyme, Lavender, German chamomile, Peppermint, Palma rosa, Eucalyptus globulus, Eucalyptus citriodora, Lemongrass and Rose) against multiply resistant organisms. Twenty five strains of Methicillin Resistant Staphylococcus aureus (MRSA), ten strains of vancomycin resistant Enterococcus sp. (VRE), and 5 strains of extended spectrum beta-lactamase (ESBL) or Amp C resistant gram negative rods were tested. An aromatogram (Bauer- Kirby [KB]), killing curve, and synergy tests were performed against the isolates. Organisms were classified as multiply resistant using NCCLS approved methods. The bacteria were obtained from the Pinnacle Health microbiology repository. The ten EO were tested in three phases.
\end{abstract}

Antimicrobial activity occurred between several EO and the multiply resistant bacteria. Lemongrass, Thyme and Palma rosa oils were the most active compounds overall. The Lemongrass and Thyme were the most active compounds versus MRSA. Lemongrass and Palma rosa showed the greatest activity versus VRE and Tea Tree and Thyme showed the most activity against resistant gram negative rods. EO shows antimicrobial activity versus multiply resistant bacteria in vitro. More studies are needed to confirm this activity in vivo.

Keywords: Essential Oils, Antimicrobial Resistance, Multi Drug Resistant Organsims

\section{Introduction}

Antibiotic resistance is an increasing worldwide phenomenon [1-4]. It is at least partially driven by the overuse of antibiotics, particularly broad-spectrum antibiotics and has been occurring for many years without resolution [5-8]. Physicians, hospitals, drug companies, and government agencies have been looking for new and innovative ways to deal with these resistant strains of bacteria. Over the last few decades, a decrease in the number of new antibiotics have been realized [1]. Between 1983 and 1987 16 new antibiotics were approved while only 2 new antibiotics were introduced between 2008 and 2012. In addition, antibiotic resistance is increasing worldwide [1]. Essential oils (EO) have been used since ancient times for healing and the treatment of patients [9], recently, there is an interest in them as an alternative to antimicrobial therapy as a replacement or as an adjunctive therapy source [10]. There has been an interest in using essential oils (E0) both in and out of the hospital [10].

The purpose of this study is to evaluate the activity of 10 EO, (Tea tree, Thyme, Lavender, German chamomile, Peppermint, Palmarosa, Eucalyptus globulus, Eucalyptus citriodora, Lemongrass and Rose, see table 1 against multiply resistant organisms using standard methods [10].

\section{Methods}

Twenty five strains of Methicillin Resistant Staphylococcus aureus (MRSA), ten strains of vancomycin resistant Enterococcus sp. (VRE), and 5 strains of extended spectrum beta-lactamase 
(ESBL) or Amp C resistant gram negative rods were tested. An aromatogram (Bauer- Kirby [KB]), killing curve, and synergy tests were performed against the isolates [10-12].

Organisms were collected from distinct geographical regions (Illinois, Michigan, North Carolina and Pennsylvania) and stored in the Pinnacle Health microbiology repository. This was done in an attempt to test separate clones of organisms and prevent testing multiples of the same organisms. Organisms were classified as multiply resistant using NCCLS approved methods $[13,14]$. The ten EO (Table 1) were tested in three phases.

\begin{tabular}{|c|c|c|}
\hline \multicolumn{4}{|c|}{ Table 1: Ten Essential Oils for in-vitro Study. } \\
\hline 1 & Melaleucaalternifolia Ctterpineol & Tea Tree \\
\hline 2 & Lavandulaangustifolia & True Lavender \\
\hline 3 & Mentha xpiperita & Peppermint \\
\hline 4 & Eucalyptus globulus & Eucalyptus globulus \\
\hline 5 & Eucalyptus citriodora & Eucalyptuscitriodora \\
\hline 6 & Cymbopogonmartinii & Palmarosa \\
\hline 7 & Cymbopogoncitratus & Lemongrass \\
\hline 8 & Matricariarecutita & German Chamomile \\
\hline 9 & Rosa damascena & Rose \\
\hline 10 & Thymus vulgaris CT linalool & Thyme \\
\hline
\end{tabular}

The antimicrobial activity of the essential oils was studied using three phases as described below. Phase I: 10 EO were tested versus 25 Methicillin Resistant Staphylococcus aureus (MRSA), 10 Vancomycin Resistant Enterococcus $s p$ (VRE) and 5 Escherichia coli and Klebsiella pneumoniae (ESBL/ AmpC) isolates using an aromatogram. Control organisms suggested by NCCLS (obtained from the American Type Culture Collection were also tested $[13,14]$.

Essential oils tested versus the aforementioned organisms were; Tea Tree, Thyme, Lavender, German chamomile, Peppermint, Palmarosa, Eucalyptus globulus, Eucalyptus citriodora, Lemongrass and Rose. Three $\mu$ l of each of the oils were placed onto separate blank susceptibility disks (Becton Dickinson BBL, Franklin Lakes, New Jersey) and allowed to absorb.

The Phase I test were setup as previously described and suggested as a preliminary screening method [11]. The inoculum of bacteria in saline was calibrated to a $0.5 \mathrm{Mc}$ Farland standard $\left(10^{8} \mathrm{cfu}\right.$ (colony forming units) $\left./ \mathrm{ml}\right)$. While the disks were soaking, a $0.01 \mathrm{ml}$ inoculum of the test organisms were streaked on topetri dishes filled with Mueller Hinton agar (Mueller Hinton agar plates with 5\% sheep's blood for the VRE cultures) (Becton Dickinson BBL, Franklin Lakes, New Jersey). The disks were placed onto the Mueller Hinton agar plates, 6 disks per plate. All tests were done in duplicate. The plates were then incubated for 24 hour at $35^{\circ} \mathrm{C}$ in room air. The zone diameters were measured and recorded. The average zone diameters of duplicate tests were used.

Phase II: 5 EO were tested against 7 microorganisms (showing variable results) by exposing them to the EO diluted in a fixed oil (suspensions used in vivo) in a test tube and measuring a killing curve for each EO and microorganism. Based upon the results of the first experiment, additional tests, "killing curves" were performed. Tea Tree, Lemongrass, Thyme linalooland German chamomile were used in this phase of the study. These oils were chosen because they were the best and the worst inhibitors in Phase I tests. The oils were mixed with a carrier oil, Sweet Almond oil (Prunusdulcis) in a sterile tube and then inoculated with a test organism $\left(10^{8} \mathrm{cfu} /\right.$ $\mathrm{ml}$ ) and covered with parafilm. They were then subbed out and streaked onto a plate at one, two, three, six, and 24 hours after they were placed into the oil. All subcultures were performed in duplicate. The plates were incubated as above. Colony counts of the subculture plates were performed. The average colony counts found upon duplicate tests were used in the study.

Phase III: Synergy/antagonism was tested between the fixed oil with or without vitamin E and 4 EO versus the multiply resistant micro-organisms. Phase III was initiated since the carrier oil showed inhibition. A synergy test was performed similar to testing in Phase I. Disks impregnated with Sweet Almond Oil. Sweet Almond Oil was placed adjacent to a disk containing one of the other test oils from the killing curve onto agar plates at $10 \mathrm{~mm}$ and $15 \mathrm{~mm}$ apart. Blunting (antagonism) or enhanced inhibition (synergy) was recorded between Sweet Almond Oil and each other test oil.

\section{Results}

Antimicrobial activity occurred between several EO and the multiply resistant bacteria. Lemongrass, Thyme linalool and Palmarosa oils were the most active compounds overall. The Lemongrass and Thyme were the most active compounds versus MRSA. Lemongrass and Palmarosa showed the greatest activity versus VRE and Tea Tree and Thyme linalool showed the most activity against resistant gram negative rods. EO show antimicrobial activity versus multiply resistant bacteria in vitro. More studies are needed to confirm this activity in vivo. (Table 2 , Figure $1 \& 2$ ). 


\begin{tabular}{|c|c|c|c|}
\hline \multirow{2}{*}{ Table 2: Phase 1- Zone Diameter Results of Multi-Resistant Organisms versus Essential Oils. } & MRSA \\
\hline & $\begin{array}{c}\text { VRE } \\
\text { Everage 10 strains } \\
\text { *Zone Diameter in MM }\end{array}$ & Average 25 strains & ESBL/AMPC \\
\hline Tea Tree & $6^{*}$ & 11.5 & 14.8 \\
\hline True Lavender & 6.1 & 12.48 & 10.2 \\
\hline Peppermint & 8.5 & 13 & 6 \\
\hline Eucalyptus globulus & 6 & 6.52 & 6 \\
\hline Eucalyptus citriodora & 6.6 & 6.44 & 6 \\
\hline Palmarosa & 12.1 & 13.64 & 6 \\
\hline Lemongrass & 17 & 24.48 & 6 \\
\hline German chamomile & 6 & 6 & 6 \\
\hline Rose & 8.2 & 10.88 & 12.6 \\
\hline Thyme linalool & 8.7 & 14.75 & 6 \\
\hline
\end{tabular}

Killing Curve
Results for ESBL
Producers
(Escherichia coli and
Klebsiella pneumoniae)

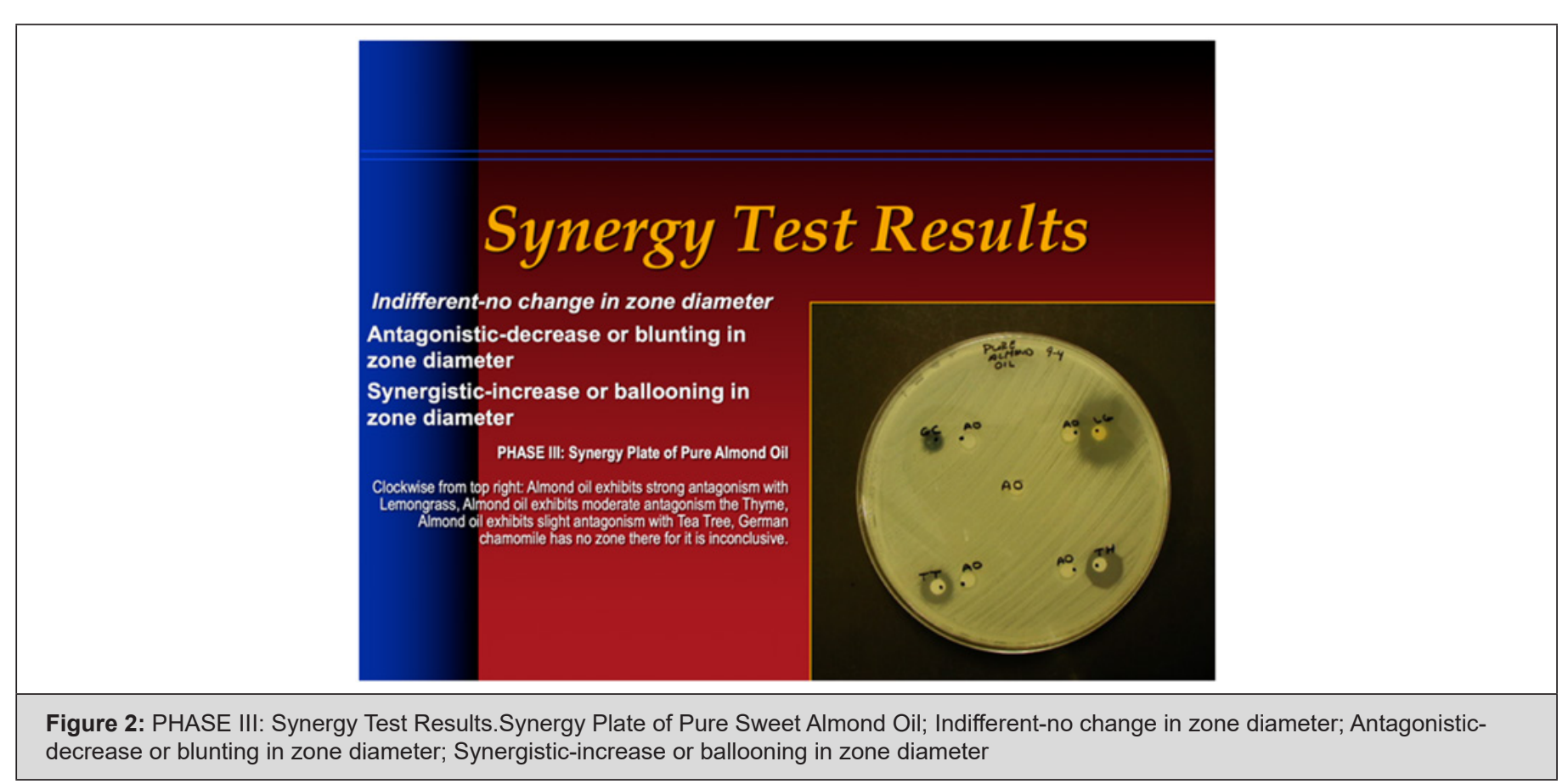


*Clockwise from top right: Sweet Almond oil exhibits strong antagonism with Lemongrass, Sweet Almond oil exhibits moderate antagonism the Thyme linalool, Sweet Almond oil exhibits slight antagonism with Tea Tree, German chamomile has no zone there for it is inconclusive.

\section{Conclusions}

In Phase I the results are consistent with other studies looking at ranges of zone diameters [11]. In the current study the most inhibitory essential oil was Lemongrass against VRE and MRSA. The most inhibitory essential oil against ESBL/AmpC strains was Tea Tree. The least inhibitory essential oil against all the bacteria tested was German chamomile. Consistent results were observed when measuring the zone diameters of inhibition. Some limitations of this testing may be the activity of the solvent as recognized in the current study, the volume of EO on the susceptibility disks and the thickness of the agar layer [11].

In Phase II , of the essential oils tested, Lemongrass and Tea Tree had the most significant killing effect. A control test tube of almond oil (without any essential oil added) also killed the bacteria. Since the almond oil appeared to kill the bacteria faster alone than mixed with essential oil we decided a third phase of the study was necessary.

In Phase III we discovered that the carrier oil often used by aromatherapists in conjunction with essential oils had varying antagonistic effects on the essential oils' antimicrobial activity. In this phase the almond oil alone did not produce zones of inhibition. We believe this happened because the almond oil was too viscous to diffuse through the agar medium.

In the current study, the solvent (Sweet Almond Oil) showed antagonism with several of the EO studied and showed difficulty in diffusion in the test method. Different parameters in this test could affect the result, such as the volume of EO on the paper discs, the thickness of the agar layer and the solvent. As previously seen, this could result in difficulty in reproducibility of screening methods [11,15-17]. An important parameter in phase I is that the zone diameters seen are reproducible in each of the EOtested and are consistent with those seen in other studies [11]. As demonstrated in the current study, a disk test is useful in screening for antibacterial activity of EO, however further studies maybe needed to determine the best EO and solvent to be used for medicinal therapy.

As evidenced in other studies [18], Lemongrass and Tea Tree oil were effective in killing organisms in vitro and in our study did it faster than the other oils. Natural products are interesting alternative or supplemental to antibiotics as a treatment moiety for patients inside and outside the hospital.

\section{References}

1. Sautter RL, Halstead DC (2018) Need of the hour: addressing the challenges of multi-drug-resistant health care-associated infections and the role of the laboratory in lowering infection rates. Clin Microbiol Newsletter 40: 11-16.

2. (2017) Centers for Disease Control and Prevention. Posting date. Core elements of hospital antibiotic stewardship programs. Centers for Disease Control and Prevention.

3. Halstead DC, Sautter RL (2018) New paradigm, new opportunities: laboratory stewardship. Clin Micro News 40(21): 175-180.

4. Barlam TF, Cosgrove SE, Abbo LM, MacDougall C, Schuetz AN, et al. (2016) Implementing an antibiotic stewardship program: guidelines by the Infectious Diseases Society of America and the Society for Healthcare Epidemiology of America. Clinical infectious diseases: an official publication of the Infectious Diseases Society of America 62(10): e51-77.

5. Gold HS, Moellering RC (1996) Antimicrobial-drug resistance. N Engl J Med 335: 1445-1453.

6. Murray BE (1994) Can antibiotic resistance be controlled? N Engl J Med 330: 1229-1230.

7. Murray BE, Moellering RC (1978) Patterns and mechanisms of antibiotic resistance. Med Clin North Am 62: 899-923.

8. Neu HC (1992) The crisis in antibiotic resistance. Science 257: 10641072

9. Elshafie, Hazem S, Ippolito Camele (2017) An Overview of the Biological Effects of Some Mediterranean Essential Oils on Human Health. BioMed research international 2017: 9268468.

10. Mammad Z, Hsaine S, Djassinra T, Ounine K (2018) The Antibacterial and Antioxidant Effect of Salvadorapersica on Antibiotic Resistant Strains. American Journal of Plant Sciences 9: 1478-1485.

11. Tajkarimi MM, Ibrahim SA, Cliver DO (2010) Antimicrobial herb and spice compounds in food. Food Control 21: 1199-1218.

12. Gadisa E, Weldearegay G, Desta K, Getahun Tsegaye, Sityehu Hailu, et al. (2019) Combined antibacterial effect of essential oils from three most commonly used Ethiopian traditional medicinal plants on multidrug resistant bacteria. BMC Complement Altern Med 19: 24.

13. Clinical Laboratory Standards Institute (CLSI) 2018 Performance Standards for Antimicrobial Susceptibility Testing: Twenty-Eighth Informational Supplement M100- S28. CLSI Wayne, PA, USA.

14. Clinical Laboratory Standards Institute (CLSI) 2018 Performance Standards for Antimicrobial Disk Susceptibility Tests: Approved Standard-Thirteenth Edition. CLSI document M02-A13. CLSI Wayne, PA, USA.

15. Brandi G, Amagliani G, Schiavano GF, De Santi M, Sisti M (2006) Activity of Brassica oleracea leaf juice on food borne pathogenic bacteria. Journal of Food Protection 69(9): 2274-2279.

16. Burt SA, Der Zee RV, Koets AP, De Graaff AM, Van Knapen F, et al. (2007) Carvacrol induces heat shock protein 60 and inhibits synthesis of flagellin in Escherichia coli 0157:H7. Applied and Environmental Microbiology 73: 4484-4490.

17. Kil HY, Seong ES, Ghimire BK, Chung IM, Kwon SS, et al. (2009) Antioxidant and antimicrobial activities of crude sorghum extract. Food Chemistry 115: 1234-1239.

18. Patterson JE, McElmeel L, Wiederhold NP (2019) In Vitro Activity of Essential Oils against Gram-Positive and Gram-Negative Clinical Isolates, Including Carbapenem-Resistant Enterobacteriaceae. Open Forum Infect Dis 6(12): ofz502. 